\title{
Williams-Beuren syndrome: An unusual cause of neonatal and infantile coarctation
}

\author{
Issam Kammache, $\mathrm{MD},{ }^{\mathrm{a}}$ Philippe Acar, $\mathrm{MD}, \mathrm{PhD},{ }^{\mathrm{b}}$ Bernard Kreitmann, $\mathrm{MD}, \mathrm{PhD},{ }^{\mathrm{a}}$ and \\ Alain Fraisse, $\mathrm{MD}, \mathrm{PhD},{ }^{\mathrm{a}}$ Marseille and Toulouse, France
}

Williams-Beuren syndrome (WBS), a genetic disease involving the elastin gene, is characterized by elfin face and mental and growth retardation. Cardiovascular involvement primarily comprises supravalvular aortic stenosis and peripheral pulmonary stenosis. Neonates with WBS are commonly asymptomatic, ${ }^{1}$ although a few articles report with the presence of aortic coarctation (COA) ${ }^{1-5}$ We sought to determine the frequency and the clinical profile of infants with WBS and COA.

\section{CLINICAL SUMMARIES}

A retrospective review (January 1996-June 2007) of all infants less than 3 months old admitted in our institution for COA repair identified $3(2.2 \%)$ of 135 with WBS.

\section{Patient 1}

A 10-day-old baby boy $(3.1 \mathrm{~kg})$ had moderate COA. Echocardiography showed no supravalvular aortic stenosis, a normally developed aortic arch with discrete isthmic COA, a closed ductus arteriosus, and normal pulmonary arteries. There was neither hypercalcemia nor dysmorphia. Surgery at 1 month via a left throracotomy comprised end-to-end anastomosis with polytetrafluoroethylene (Gore-Tex patch; W. L. Gore \& Associates, Inc, Flagstaff, Ariz) patch enlargement of the descending aorta. Because of pathologic findings showing collagen-rich fibrous tissue with smooth muscle cells in the intima and a hypertrophied media, WBS was suspected and confirmed by fluorescence in situ hybridization (FISH) analysis. At 3 months, transcatheter balloon dilation for severe recoarctation only decreased the peak-to-peak gradient from 60 to $30 \mathrm{~mm} \mathrm{Hg}$. The child was subsequently lost to follow-up. He was seen again at 11 years of age with severe hypertension and a $100 \mathrm{~mm}$ $\mathrm{Hg}$ systolic upper-to-lower limb gradient. Computed tomog-

From Cardiologie Pédiatrique médico-chirurgicale, ${ }^{\mathrm{a}}$ Hôpital de la Timone-Enfants, Marseille, France; and Cardiologie Pédiatrique, ${ }^{\mathrm{b}}$ Département médico-chirurgical de pédiatrie, Hôpital des Enfants, Toulouse, France.

Disclosures: None.

Received for publication July 2, 2010; accepted for publication July 27, 2010; available ahead of print Sept 13, 2010.

Address for reprints: Alain Fraisse, MD, PhD, Pediatric Cardiology Department, La Timone Children's Hospital, 264 rue Saint Pierre, 13385 Marseille Cedex 05,

France (E-mail: alain.fraisse@ap-hm.fr).

J Thorac Cardiovasc Surg 2010;140:e80-1

$0022-5223 / \$ 36.00$

Copyright (c) 2010 by The American Association for Thoracic Surgery

doi: $10.1016 /$ j.jtcvs. 2010.07 .063

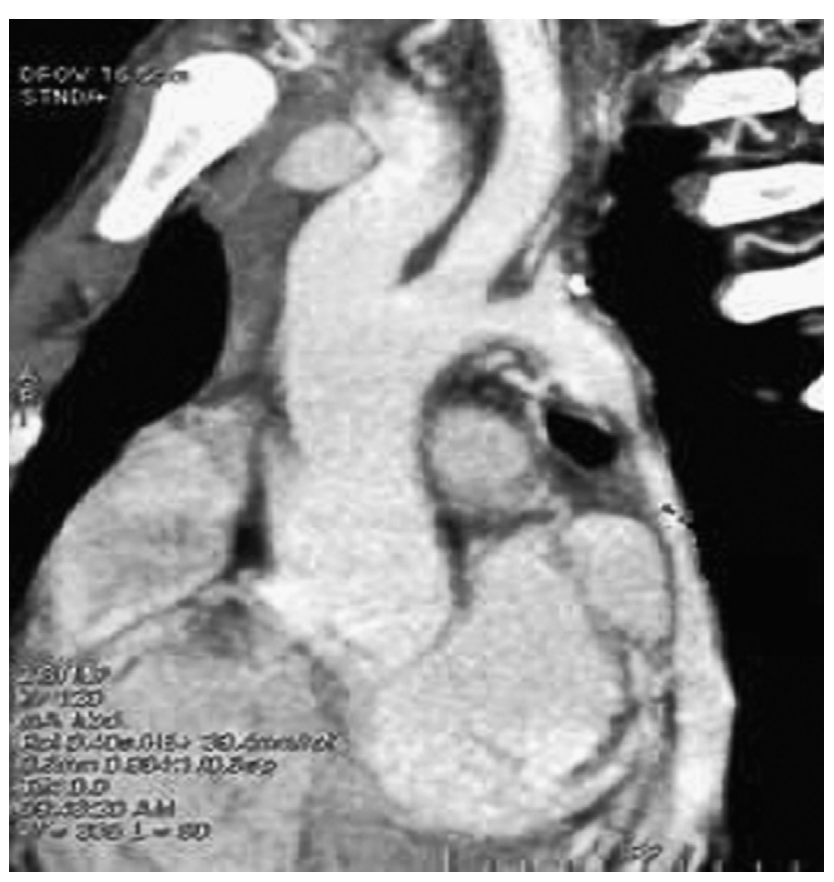

FIGURE 1. Computed tomogram showing a severe and irregular hypoplasia of the descending thoracic aorta.

raphy showed tortuous hypoplasia of the thoracic aorta (Figure 1). Surgery was performed with the implantation of a 16-mm Dacron conduit between the ascending and the descending aorta. Follow-up for the next 3 years demonstrated no residual aortic obstruction.

\section{Patient 2}

A 2-day-old baby boy weighing $2.5 \mathrm{~kg}$ had a cardiac murmur and weak femoral pulses. Echocardiography showed an ostium secundum atrial septal defect, an unrestrictive perimembranous ventricular septal defect, no supravalvular aortic stenosis, moderate hypoplasia of the aortic arch, isthmic COA, and a closed ductus arteriosus. The pulmonary arteries were normal. There were no extracardiac features. At 6 weeks, surgery through a median sternotomy with cardiopulmonary bypass comprised COA resection with end-to-end anastomosis, polytetrafluoroethylene patch enlargement of the aortic arch, and closure of ventricular and atrial septal defects. WBS was suspected intraoperatively because of thickness of the aortic wall and confirmed by FISH analysis. At 4 months, transcatheter balloon dilation relieved a severe recoarctation $(65 \mathrm{~mm} \mathrm{Hg}$ 
peak-to-peak gradient). Re-recoarctation occurred, necessitating reoperation at 15 months. The aortic arch was enlarged with a bovine patch (Cardiofix pericardium; Carbomedics, Inc, Arvada, Colo). Follow-up for $3 \frac{1}{2}$ years demonstrated no residual aortic obstruction.

\section{Patient 3}

A $2^{1} / 2$-month-old baby boy weighing $4 \mathrm{~kg}$ had COA. Echocardiography showed discrete isthmic COA, closed ductus arteriosus, bicuspid aortic valve, and normal pulmonary branches. FISH analysis performed because of hypercalcemia confirmed WBS. Surgery comprised an end-to-end anastomosis. Complete resection of all pathologic tissue was not feasible because the narrowing of the descending aorta extended too far distally. Postoperatively, mild COA persisted with a systolic gradient of 25 $\mathrm{mm} \mathrm{Hg}$. Reoperation at 6 months was performed with patch enlargement of the thoracic descending aorta. Follow-up for 3 years demonstrated no residual aortic obstruction.

\section{DISCUSSION}

Neonatal diagnosis of WBS is difficult because the syndrome usually occurs sporadically and the striking physical and behavioral features are rarely recognizable. Rather, patients typically present after 1 year of age. ${ }^{1,2}$ Moreover, conversely to older children in whom supravalvular aortic stenosis and/or peripheral pulmonary stenosis are often associated, ${ }^{1} \mathrm{COA}$ is often isolated in infants with $\mathrm{WBS}^{2-5} \mathrm{Fi}^{-}$ nally, although COA in infantile WBS may take the atypical form with extension far beyond the isthmus in the so-called middle aortic syndrome, ${ }^{5}$ it rather mimics a typical neonatal COA, as in our 3 cases. However, infantile COA in the setting of WBS is not exceptionally encountered. In a recent study focusing on 129 cases of infantile WBS, COA was the fourth more frequent cardiovascular lesion, in $19 \%$ of $_{\text {cases. }}{ }^{2}$ Our case series suggests that WBS might be encountered in approximately $2 \%$ of cases pf neonatal or infantile COA.

Recoarctation occurred in our 3 patients after initial surgery, similar to the 3 previously published cases of WBS with neonatal COA. ${ }^{3-5}$ Transcatheter balloon dilation seems disappointing to treat recoarctation in WBS, and stent implantation is not appropriate in small infants. The appropriate treatment is probably surgery with patch enlargement and even sometimes exclusion of the stenotic aortic segment.

We acknowledge Michel Voisin, MD, from Hôpital Arnaud de Villeneuve, Montpellier, France, for patient referral, and Phalla $\mathrm{Ou}, \mathrm{MD}, \mathrm{PhD}$, from Hôpital Necker-Enfants-Malades, Paris, France, for providing computed tomography images.

\section{References}

1. Pham PP, Moller JH, Hills C, Larson V, Pyles L. Cardiac catheterization and operative outcomes from a multicenter consortium for children with Williams syndrome. Pediatr Cardiol. 2009;30:9-14.

2. Collins RT, Kaplan P, Somes GW, Rome JJ. Cardiovascular abnormalities, interventions, and long-term outcomes in infantile Williams syndrome. J Pediatr. 2010;156:253-8.

3. Arrington C, Tristani-Firouzi M, Puchaliski M. Rapid progression of longsegment coarcation in a patient with Williams' syndrome. Cardiol Young. 2005; 15:312-4.

4. Marks JL, Mitchell MB, Campbell DN, Toews WH. Composite aortoplastie for recurrent coarctation after neonatal repair in Williams syndrome. Ann Thorac Surg. 2004;77:319-21.

5. Hall EK, Glatz J, Kaplan P, Kaplan BS, Hellinger J, Ernst L, et al. A case report of rapid progressive coarctation and severe middle aortic syndrome in an infant with Williams syndrome. Congenit Heart Dis. 2009;4:373-7.

\title{
Aortic dissection caused by aortitis associated with hepatitis C virus-related cryoglobulinemia
}

\author{
Naoto Fukunaga, MD, Hiroshi Fujiwara, MD, Michihiro Nasu, MD, and Yukikatsu Okada, MD, Kobe, Japan
}

\footnotetext{
From the Department of Cardiovascular surgery, Kobe City Medical Center General Hospital, 4-6 Minatojimanakamachi, Chuo-ku, Kobe, Hyogo 650-0046, Japan. Disclosures: None.

Received for publication June 29, 2010; accepted for publication July 11, 2010; available ahead of print Aug 23, 2010.

Address for reprints: Naoto Fukunaga, MD, Department of Cardiovascular Surgery, Kobe City Medical Center General Hospital, 4-6 Minatojimanakamachi, Chuoku, Kobe, Hyogo 650-0046, Japan (E-mail: naotowakimachi@hotmail.co.jp).

J Thorac Cardiovasc Surg 2010;140:e81-2

$0022-5223 / \$ 36.00$

Copyright (c) 2010 by The American Association for Thoracic Surgery

doi:10.1016/j.jtcvs.2010.07.021
}

Cryoglobulinemia can generally cause systemic vasculitis to small and medium-sized vessels, not to great vessels, resulting in neuropathy, renal impairment, and coagulopathy. To our knowledge, this is the first description of acute aortic dissection caused by aortitis associated with hepatitis C virus-related cryoglobulinemia.

\section{CLINICAL SUMMARY}

A 71-year-old man was referred for emergency surgery for acute type A aortic dissection in an intubated state. $\mathrm{He}$ 